\title{
Situated, embodied and social problem-solving in virtual worlds
}

\author{
Andrew Cram ${ }^{\mathrm{a} *}$, John G. Hedberg ${ }^{\mathrm{a}}$, Maree Gosper ${ }^{\mathrm{a}}$ and Geoff Dick ${ }^{\mathrm{b}}$ \\ ${ }^{a}$ Department of Education, Macquarie University, Sydney, NSW, Australia; ${ }^{b}$ College of \\ Business, North Georgia College and State University, Milledgeville, GA, USA
}

(Received 30 January 2011; final version received 12 September 2011)

\begin{abstract}
Contemporary theories of problem-solving highlight that expertise is domain specific, contingent on the social context and available resources, and involves knowledge, skills, attitudes, emotions and values. Developing educational activities that incorporate all of these elements is a challenge. Through case studies, this paper outlines how situated, embodied and social problem-solving activities within virtual worlds can elicit responses that engage all facets of expertise.
\end{abstract}

Keywords: problem-solving; expertise; attitudes; emotions; values

\section{Introduction}

In recent years, there have been two trends in theories of problem-solving. The first is a shift from domain-general conceptualisations of problem-solving towards domain-specific models (Jonassen 2000), which recognise that the ability to resolve unfamiliar problems is less contingent on possessing a general process of problemsolving than on being able to interpret and respond to a specific situation in effective ways. This view places an emphasis on the impact of the social and environmental context from which the problem has emerged. The second trend is that it is increasingly being recognised that problem-solving expertise is not only dependent on a person's knowledge and skills, but also relies on attitudes, values and other social factors (Hatano and Oura 2003). A challenge for educators is to develop activities that equip learners with these facets of expertise.

One approach for educators is to develop contextualised problem-solving challenges that elicit both cognitive and affective responses from students. These designed experiences (Squire 2006) would involve problematic situations that encourage learners to consider the range of experiences and interpretations that emerge from social interactions. Virtual worlds offer intriguing opportunities for achieving this aim, providing a four-dimensional space in which learners can participate in a narrative to engage with and resolve problems through social interactions and use of situational resources.

This paper discusses current theories and educational perspectives of expertise. Then, the potential contribution of virtual worlds is outlined and illustrated through two case studies involving a problem-solving challenge situated in an organisational setting. The analysis and discussion examines the extent that the challenge invokes responses that involve attitudinal, cognitive and social facets of expertise.

*Corresponding author. Email: andrew.cram@students.mq.edu.au 


\section{Problem-solving expertise}

Problems can be conceptualised along a continuum of well-structured to ill-structured. Well-structured problems have "absolutely correct and knowable" solutions, while illstructured problems may have "conflicting assumptions, evidence, and opinion that may lead to different solutions" (Kitchener 1983, 223). This distinction is important because well-structured problems are best resolved by applying a specific process, while resolutions to ill-structured problems require more divergent approaches that use the situational specifics of the problem (Jonassen 1997), sometimes referred to as adaptive expertise (Hatano and Inagaki 1984).

For many years, theories of problem-solving were advanced through models of information processing, seeking to explain the mental processes people use to accomplish tasks. Research focused on areas such as memory, pattern matching and the differences between experts and novices (Chi and Glaser 1988), leading to generic problem-solving models (for example, Gick 1986; Newell and H.A. Simon. 1961).

Some findings contrasted with efforts to develop generic problem-solving models. For example, studies reveal impediments to transferring expertise between domains (Chi and Glaser 1988), and that expertise with well-structured problems does not correlate to expertise with ill-structured problems (Schraw, Dunkle, and Bendixen 1995). Developing expertise in a complex domain can take around 10,000 hours of practice (Ericsson and Charness 1994).

Bransford, Brown, and Cocking $(1999,19)$ have summarised this research with six key principles:

(1) Experts notice features and meaningful patterns of information that are not noticed by novices.

(2) Experts have acquired a great deal of content knowledge that is organised in ways that reflect a deep understanding of their subject matter.

(3) Experts' knowledge cannot be reduced to sets of isolated facts or propositions but, instead, reflects contexts of applicability: that is, the knowledge is 'conditionalised' on a set of circumstances.

(4) Experts are able to flexibly retrieve important aspects of their knowledge with little attentional effort.

(5) Although experts know their disciplines thoroughly, this does not guarantee that they are able to teach others.

(6) Experts have varying levels of flexibility in their approach to new situations.

The domain specificity of expertise has been further explored through a situated perspective of problem-solving. In particular, this has highlighted that problemsolving experiences are shaped by, and in turn shape, the context from which the problem emerges (Lave 1988). Jonassen (2000, 65) has argued that different illstructured problems "are not equivalent, in content, form, or process", and that learners need to develop different forms of expertise for different situations.

Research by Lave (1988) illustrates how people structure their problem interpretations and responses through the artefacts available within the situation. In one example (Lave 1988, 154), a shopper suspects that a piece of cheese has an incorrect price so compares the price with another piece of cheese that looks the same size. This approach is contrasted to an alternative method that would have been favoured under the information-processing approach: to identify the 'price per pound' and weight on the label and mentally calculate the correct price. The point 
made by Lave is that although the problem could have been resolved using mental calculation of symbols, the shopper opted for a solution that utilised the presence of another piece of cheese of similar size.

The implication is that a person's domain knowledge in relation to a specific problem is contingent on the situational context including the available resources. However, this remains a relatively narrow view of problem-solving - other researchers have highlighted that effective problem-solving is also influenced by attitude, emotions and values.

A person's attitude represents an evaluation of something (such as another person, an object, a behaviour or a policy) that has arisen as beliefs are formed about that entity (Ajzen 2001; Ajzen and Fishbein 1977). It is generally accepted that attitudes influence a person's overall pattern of responses towards something, although they have a low predictive utility for any specific action (Ajzen and Fishbein 1977; Glasman and Albarracin 2006). Attitudes are also relevant to problem-solving because they can influence self-confidence, motivation and perseverance (Jonassen 2000). This is particularly relevant within education, as learners' attitudes towards school subjects such as science can influence problem-solving expertise within that domain (Shin, Jonassen, and McGee 2003).

Emotion refers to general moods such as happiness and specific responses such as anger (Ajzen 2001). Emotions are pervasive in human activity (Camerer, Loewenstein, and Prelec 2005; Damasio 2000) and can impact decision-making at the time of the decision, after the decision, and through anticipation or memories of past affect (Schwarz 2000). For example, happiness and sadness influence experimental responses across a range of cognitive phenomena that involve interpretation, memory and judgement (Clore and Huntsinger 2007).

A person's values will modulate their response to an ethically nuanced situation (Forsyth, O'Boyle, and McDaniel 2008). Traditionally, explicit moral reasoning was argued to drive responses; however in line with the above discussion, contemporary theories are arguing for increased consideration of intuition (Cushman, Young, and Hauser 2006) and identity (Shao, Aquino, and Freeman 2008).

Hatano and Oura (2003) have synthesised current theories of expertise to extend the list of key principles provided by Bransford, Brown, and Cocking (1999). Not only do experts have certain cognitive characteristics, but there are also important social and affective factors: as expertise is developed, there are socio-emotional changes relating to interests, values and identity; other people and artefacts assist expertise development; in expertise development, learning is intertwined with solving socially significant problems and tasks; and expertise is distributed (Hatano and Oura 2003, 26). Shaffer outlines the notion that people act and solve problems through epistemic frames, which are ways of:

knowing where to begin looking and asking questions, knowing what constitutes appropriate evidence to consider or information to assess, knowing how to go about gathering that evidence, and knowing when to draw a conclusion and/or move on to a different issue. (2006, 227-228)

This perspective complements the synthesis by Hatano and Oura (2003) by emphasising the specific practices that people perform to resolve problems and proposing a mechanism by which these practices are transferred between different settings. 
This sets educators a considerable challenge: to engage students in activities that will develop not only domain knowledge and skills, but also appropriate attitudes, emotional regulation and appreciation of values. Additionally, expertise is applied in a broader social context and is mediated by artefacts, and this can be difficult to set up within a classroom setting.

In recent years, educational design approaches have been developed that consider the cognitive aspects of problem-solving from the situated perspective, in which concepts are considered as tools and knowledge is accumulated through activities that mimic contexts of use (cf. Brown, Collins, and Duguid, 1989). Theories of authentic learning, for example, hold that educators should "provide contexts that reflect the way the knowledge will be used in real life" (Herrington and Oliver 2000, 26), with the objective of maximising "cognitive realism" (Herrington, Reeves, and Oliver, 2007, 96).

As argued by Hatano and Oura (2003), educators should also consider the socio-emotional aspects of expertise development. To facilitate this, problem-solving challenges could be designed to elicit responses that are modulated by learners' attitudes, emotions and values, so that these facets of expertise may be practised, observed, discussed and reflected upon. Virtual worlds offer one potential platform to support such challenges.

\section{Virtual worlds}

Virtual worlds are electronic environments that mimic three-dimensional space, in which people may assume an embodied persona (an avatar) and may interact with each other and with virtual objects (Bainbridge 2007; Schultze et al., 2008). The term 'virtual world' is used broadly, including both multi-user virtual environments such as Second Life and games environments such as Crysis. Virtual worlds are being used within education across wide range of domains, including business, arts, health, science, engineering, and military training (Gregory et al., 2010; Ulicsak \& M. Wright. 2010). Virtual worlds support design of contextualised experiences for learners (Squire 2006), particularly through the use of interactive narratives to shape that experience (Barab et al., 2007). The persistent, yet malleable, nature of virtual worlds allows these narratives to be played out multiple times, or modified to set up differing situations.

Central to the shift in perspective to considering socio-emotional aspects of expertise is a focus on problem-solving in social situations. In virtual worlds, the re-embodiment of users through avatars is thought to contribute to the complexity of the social interactions that can take place. While this is an emerging field of research, several researchers have noted that avatars are given particular consideration and provide a focus for social interaction (Mennecke et al., 2011; Slater et al., 2000; Taylor 2002). Interactions through avatars also contribute to feelings of copresence, or the feeling of being with other people (Peterson 2006). Mennecke and colleagues $(2011,414)$ propose a model to explain how a sense of presence arises from embodied social interactions through avatars, arguing that "when social actors experience this higher level of embodied interaction, they more effectively encode, convey, and decode individual and collective communicative acts". They also argue that a sense of embodied social presence during communication can occur without an avatar; for example, through a voice or text conversation when attention is focused on the task or the other person. 
In this paper, we argue that virtual worlds can be designed to elicit problemsolving responses in which learners consider and experience emotions, attitudes and values as well as cognitive challenges. This could be conceptualised as a type of epistemic game (Shaffer 2006) that is designed to reveal a learner's epistemic frame shaped by both attitudinal and cognitive considerations. Below, two case studies are presented that demonstrate how problem-solving challenges can be designed within virtual worlds in ways that align with contemporary theories of expertise.

\section{Method}

Guided by theories of situated, embodied and social activity, an interactive narrative involving a decision-making challenge was developed within a virtual world. The scenario, described in detail below, was set up as a research experiment, and was not integrated into a specific educational course or programme. Nine volunteers with varying experience with virtual worlds individually completed the scenario. Each participant went through a one-hour group training session. A background information sheet was provided prior to the scenario, to orient the participant with the role and context. A debrief session was conducted at the end, to assist participants to reflect on the role and their experience.

\section{Scenario design}

Narrative

The challenge was designed to elicit a response from the participant, playing the role of Operational Health and Safety $(\mathrm{OH} \& \mathrm{~S})$ manager, to a situation occurring in a manufacturing facility. This situation involved ethical considerations relating to a safety audit. Initiating the safety audit would enable a review and improvement of worker safety conditions and practices, but would also involve the facility being temporarily shut down with contracted workers being placed on half-pay. An accident on the factory floor (a separate area from the office building) occurs during the scenario, with implications for the initiation of the safety audit. Participants are asked to make a decision concerning whether they will bring up the accident in an upcoming meeting with the Director (which is likely to result in the immediate initiation of the safety audit), or whether they will delay passing on this information to first gather more details. The scenario takes approximately 20 minutes.

\section{Problem elements}

The scenario constructs a decision-making problem, which requires recognition of the problem, generation and evaluation of alternate options, satisfaction of an external criteria, and enaction of a choice (Jonassen 2000). Participants experience a bounded snapshot of activity within the company, with only a few of the actors, locations, and resources available, within a short timescale. For example, even though the employees were referred to and the broader organisational setting implied, these were not directly accessible to participants. While the problem is not open-ended, the design was intended to be complex enough to provide problem ambiguity and multiple solutions. The emergent nature of the narrative, along with the social and embodied interactions, was intended to engender the participants' experience with affective considerations. 


\section{Social context}

The participant interacted with two actors, who played the Operations Manager (Sarah) and a Director (Tim) within the same company. Other employees of the company were alluded to. One responsibility for the OH\&S manager was to immediately inform the Director of any accidents.

\section{Spatial environment and artefacts}

The scenario took place on the ground and top floors of a four-level office building. The ground floor had a reception area and office areas for the OH\&S and Operations managers. One office presented three wall charts with data on the recent history of accidents within the plant, the current progress of machine inspections, and the planned initiatives to improve worker safety. The Director's office was on the top floor.

\section{Technology and interaction}

The scenario was developed using the Activeworlds platform. Participants could chat using audio or text, move their avatar, adjust their camera perspective, trigger gestures, and use the building's front doors and elevator. Avatars had relatively low-fidelity representations, with no support for facial expressions.

\section{Data collection}

Screen capture software was used to record participant's behaviour during the scenario. Immediately after the scenario, two interviews were conducted, asking the participant to reflect on and describe aspects of their experience during the activity. In the first interview the screen capture video was played back to the participant, who was requested to describe thoughts and feelings experienced during the activity. After this, a semi-structured interview was conducted to obtain data on specific aspects of the participant's experience that may not have been captured in the retrospective interview.

\section{Results and discussion}

In this section, we consider whether virtual worlds can be designed to engage participants in situations that require multi-faceted demonstrations of expertise, as well as examine the design elements which support this outcome. Descriptive case studies for two participants are presented, to highlight contrasts in reactions and responses to the situation. The case-study participants are referred to by a pseudonym. The discussion of the problem resolution after each case seeks to highlight how, within a relatively short and contextually bounded scenario, the experience elicited responses that were modulated by affect.

\section{Case one: Kate}

Kate had very little prior experience with virtual worlds. She initially felt nervous, but became comfortable as she grew in confidence that she could control the avatar 
as well as the situation. She felt that she was able to act within the scenario in a similar way to how she would act within her real life position. The activity was 21 minutes in length. The most significant problem encountered was the dilemma of whether to follow her role responsibilities and inform Tim (the Director) of the accident immediately, or whether to follow Sarah's (the Operation Manager) lead and delay telling him so that more information can be gathered first: "My most significant problems were in regards to the decisions that I had to make in this dilemma, as a person working for in a new organisation and my job description and the issues at hand". After the scenario, she highlighted that this decision incorporated ethical issues relating to the safety and financial welfare of the staff, as well as the responsibilities set out in her role description. Kate's experience within the scenario is outlined below, divided into sections covering prior to and during the problem, and after the decision.

\section{Prior to the problem}

After orienting Kate to the area and the scenario, Sarah led a discussion of the data on the wall charts within her office. During discussion of the number of accidents in the previous months, Kate checked the scenario background sheet, to verify how long she had been at the company and therefore which months she had responsibility for. She noted that in the months she was there improvement had been made.

After Sarah outlines the negative implications of a safety audit for the workers, Kate indicated a value judgement towards the audit: "Right, so, we absolutely have to not get there". In the retrospective interview, Kate explained that she had formed an attitude that Sarah was:

coming from the personal perspective, of, whilst we want to be safe and secure, we also have to be considerate of our staff's particular situations. She understands them from a personal point of view and so she comes from a different angle.

When the accident occurred, Kate's initial reaction demonstrated a strong understanding of corporate practices and a willingness to take charge of a situation. Her first action was to say that she should get down to first-aid, where the injured workers were. When she was informed this was not necessary as the workers were being taken care of, she began detailing the response she planned to take. This involved collecting more information by inspecting the equipment and from the injured workers and witnesses, with the aim of clarifying the cause of the accident (machine-related or human error) and determining the extent of the damage to the equipment. She also stated that, in the longer term, she would need to review the policies and procedures to check whether they are being followed. After Kate outlined her planned response, Sarah asked Kate whether she was going to inform Tim, the Director (who is not present at this time), initiating Kate's central problem.

\section{During the problem}

To clarify time constraints, Kate checked when the meeting with Tim was scheduled; and when told that they are going to Tim's office in a few minutes, her first instinct was to follow her responsibilities and inform Tim of the accident immediately. Sarah proposed an alternative response: delay telling Tim to gather more information and plan strategies that would help avoid the audit. 
Kate asked for the meeting agenda. When she found out that it is unrelated to the accident or the safety audit, she shifted her position to not informing Tim about the accident immediately, and instead gathering more information before doing so. She verbalised her plan and justification in detail, which hinged on a nuanced argument that she had heard about the accident through Sarah rather than being told directly.

Not only was this plan grounded in a rational argument, Kate's actions were reflective of the socio-emotional context. When reflecting on this part of the scenario in the retrospective interview, Kate explained: "So now I'm articulating a plan of action for after the meeting, so that she understands what I want to do after the meeting, what I need to do, and that made me feel more comfortable with that decision". After communicating the plan, Kate said to Sarah "It would be silly of me to mention that, yeah", and then "Well I think it would be silly for us to mention it until we have collected some more evidence". In the retrospective interview, Kate commented:

It's interesting, I've just changed from ... its silly for me to mention, and I've reworded it would be silly for us to mention. So I'm kind of wanting to share the responsibility for this decision or have a common understanding that this is our decision, and not just my decision as to which way we went.

\section{After the decision}

Kate and Sarah then moved to Tim's office for the meeting. Within this meeting, neither Kate nor Sarah brought up the accident. Afterwards, Kate reflected she was actively listening to check whether Sarah mentioned the accident, and that she had been feeling nervous that Tim might bring up the accident.

\section{Discussion}

Kate's response within the scenario emerged as a result of complex social relations that extended through time, including her role, her length of time within the organisation, and the ongoing implications of initiating a safety audit. She had the opportunity to utilise her domain knowledge of company practices and OH\&S, by planning a response to the accident that detailed sources of information as well as highlighting longer-term considerations involving policy and procedures.

Kate's shifting of her position (i.e. whether to inform Tim about the accident immediately) could be viewed as a rational decision, based on Sarah's argument against telling Tim immediately. However, her decision was also modulated by attitudes, emotions and values:

- Kate's initial stance towards a safety audit, was that "we absolutely have to not get there", so that the workers would not be financially disadvantaged. Her final decision was in line with this initial position.

- Kate stated in the retrospective interview that she felt that Sarah was personally involved in the workers' welfare, and this positive attitude towards Sarah may have played a role in Kate decision to follow Sarah's lead.

- When Kate was explaining her final decision and justification to Sarah, she used verbal communication in two ways: to feel more comfortable about her decision, and to communicate a joint responsibility for the decision. 
Finally, Kate's feelings towards her decision influenced how she acted later in the meeting - actively listening for certain information, and feeling nervous that Tim might bring up the accident.

\section{Case two: Emma}

Emma had a great deal of experience with virtual worlds. She was immersed within the role, stating in the subsequent interviews that "I was Emma". The scenario took 19 minutes. Her central problem was:

whether or not to listen to Sarah and do as she was asking me and not tell Tim about the explosion. Or whether to follow my conscience and tell him because of the other things I was thinking all about the safety etcetera.

This problem was ethically nuanced, primarily through consideration of the safety of the workers, but also in relation to the business implications of a safety audit. Emma's experience within the scenario is outlined below, divided into sections covering prior to and during the problem, and after the decision.

\section{Prior to the problem}

Initially, Sarah oriented Emma into the space and scenario. Sarah then led Emma to the wall charts and used them to initiate a discussion about the implications of a safety audit. Emma commented "And that will mean loss of money for us, won't it", to which Sarah affirmed that it would, but also highlighted financial implications to the workers (half-pay). During this conversation, Emma emphasised her concern for worker safety.

\section{The problem}

When the accident occurred, Emma's initial response was to say "I don't know what we can do. I think we have to report it, don't we?" Sarah then initiated a discussion of whether it might be better to delay telling Tim. Within this discussion, Emma constantly reiterated her concern for the workers' safety, and that she believed action needed to be taken immediately: "can we afford to wait?"

When reflecting on this part of the scenario, Emma commented that "Sarah was quite, forceful in her persuasion to get me not to say anything I felt", as well as that "Obviously Sarah didn't want me to say anything, but my conscience sort of said, you've just got to".

\section{After the decision}

As Emma travelled to Tim's office for the meeting, she "fell in quite a dilemma thinking what am I going to do here?" Within the meeting, Tim mentioned that funding for safety equipment was available sooner than expected. Emma was genuinely pleased with this news: "Ah, that's excellent". In the subsequent reflection, she commented:

I had an instant where I thought maybe I shouldn't say anything, because, OK, they'll get fixed. But then I thought, there's 19 machines there that have to be fixed, and you know, even if they start tomorrow it's still going to take time, and I don't think we could afford to risk it. So that's why I've decided to tell him. 
Shortly after this, Emma interrupted the agenda to inform Tim of the accident. She felt that Tim was a bit more compassionate than Sarah: "Cause at least he asked who, if anyone was injured, or how badly they were injured. Whereas Sarah seemed to be thinking more of the impact on the business". In reflection, Emma described Sarah's presence at this meeting as the biggest constraint she experienced within the scenario, explaining that she would have preferred to tell Tim "in confidence".

The scenario finished at the end of this meeting. Emma commented in her reflection: "Here I was thinking, I really don't want to go down the lift with Sarah. So I was very pleased when the scenario ended".

\section{Discussion}

Emma's problem within the scenario emerged through a conflict between her ethical imperative to ensure the workers were safe and her perception that Sarah was pushing her to cover up the incident. Compared with Kate, this problem involved fewer elements, with less consideration of the future decisions and issues that would be required as $\mathrm{OH} \& \mathrm{~S}$ manager, particularly in relation to maintaining a healthy work relationship with Sarah. In this aspect, Kate demonstrated greater commitment to considering negotiation as a critical element of shared decision-making.

Emma and Kate's contrasting attitudes towards Sarah are likely to have influenced their responses, impeding comparison of their decisions. However, this allows observation of the extent that each participant's decisions could be influenced by attitudes formed co-workers. Regulation of these attitudes is important for distributed expertise within multi-functional teams.

Emma also demonstrated ethical resilience, by maintaining her ethical stance through tension with Sarah and hesitation within the meeting with Tim. Interestingly, this hesitation was linked to a positive emotional response to the news that additional funding for safety equipment was available, demonstrating another link between emotion, values and decision-making.

The impact of participating in embodied interactions was largely absent from the data; however, one instance highlighted how this can be important. When Emma stated that she did not want to get in the lift with Sarah at the end of the scenario, she revealed how the avatar of Sarah provided a focal point for her feelings towards her. The virtual world would have allowed interaction via voice or text irrespective of them being together in the lift or not, so in that sense Sarah's presence would not have been diminished if Emma had caught the lift by herself. However, Sarah's avatar was a focus for Emma's feelings, and this comment indicated that the spatial relationship between their avatars was mediating how these feelings influenced Emma's behaviour.

\section{Conclusion}

The objective of this study was to consider how problem-solving challenges could be designed within virtual worlds in ways that align with contemporary theories of expertise. The case studies demonstrate that situations can be designed that elicit responses involving a blend of rationalisation and affective considerations. The choices made by participants were reflective of the attitudes formed towards the Operations manager and ethical considerations. Both participants also felt strong 
emotional responses, although these did not explicitly determine any decisions (Emma towards the Operations Manager, and Kate towards her shared decision to not inform the Director). OH\&S domain knowledge was also evident, particularly with Kate's immediate response to the incident outlining what information should be gathered and steps taken. Inevitably, it is difficult to reveal all motives and intentions that underpin participants' actions. However, combining observations with participant reflections clearly indicates that affective responses played a significant role.

The scenario could be considered as a type of epistemic game (Shaffer 2006) that facilitates observation of the epistemic frames that learners express through their choices. Activities such as this could be used by educators to assist learners develop in all facets of expertise, for practice, observation and reflection. Assessment of expertise may be a particularly useful application of these activities.

Designing the problem-solving challenge as a participatory narrative within a virtual world provided a fundamental grounding for the generation of cognitive and affective responses. The narrative provided structure for these responses, tying together issues and events into a spatial and social framework that unfolded in real time. Importantly, the problem emerged dynamically from within the narrative, and the problem responses were thus modulated by the attitudes, emotions and values that were generated through participation in that narrative.

The impact of the unique characteristics of the virtual world, such as embodied presence, was generally not explicitly represented in the data. However, Emma's description of her feelings towards sharing the lift with Sarah after the meeting demonstrated the potential significance of avatars as the focus of attitudes and emotional responses. The impact of embodied presence might be further increased by using avatars that support more complex forms of non-verbal communication (Weibel et al., 2010). Comparative studies with other multimedia communication technologies would also assist understanding of the role that avatars play in engendering a socio-emotional context for problem-solving.

One aspect for future consideration is: what forms of problems can be generated through narratives set within virtual worlds? This scenario set fairly restrictive boundaries on participant actions, with a generally linear progression within which the participant could make their own choices and contributions. A more open-ended situation might allow the participant to visit the site of the accident and talk to the injured workers, or have multiple meetings and consider the issues more deeply before making final decisions and recommendations.

While these case studies illustrate problem-solving in one domain, the widespread application of virtual worlds in education (Gregory et al. 2010; Ulicsak and Wright 2010) indicates that virtual worlds could also support this form of problemsolving in other domains. Additionally, while the traditional input devices for virtual worlds have offered limited control over avatars' movements, other emerging technologies such as augmented reality and motion tracking offer further potential in these areas while maintaining support for situated, embodied and social activities.

\section{References}

Ajzen, I. 2001. Nature and operations of attitudes. Annual Review of Psychology 52: 57-8.

Ajzen, I., and M. Fishbein. 1977. Attitude-behavior relations: A theoretical analysis and review of empirical research. Psychological Bulletin 84, no. 5: 888-918. 
Bainbridge, W.S. 2007. The scientific research potential of virtual worlds. Science 317, no. 5837: 472-6.

Barab, S., T.D. Sadler, C. Heiselt, D. Hickey, and S. Zuiker. 2007. Relating narrative, inquiry, and inscriptions: Supporting consequential play. Journal of Science Education and Technology 16, no. 1: 59-82.

Bransford, J.D., A.L. Brown, and R. Cocking. 1999. How people learn: Brain, mind, experience, and school. Washington, DC: National Academy Press.

Brown, J.S., A. Collins, and P. Duguid. 1989. Situated cognition and the culture of learning. Educational Researcher 18, no. 1: 32-42.

Camerer, C., G. Loewenstein, and D. Prelec. 2005. Neuroeconomics: How neuroscience can inform economics. Journal of Economic Literature 43, no. 1: 9-64.

Chi, M.T.H., and R. Glaser. 1988. Overview. In The nature of expertise, ed. M.T.H. Chi, R. Glaser, and M.J. Farr, xv-xxviii. Hillsdale, NJ: Lawrence Erlbaum Associates.

Clore, G., and J. Huntsinger. 2007. How emotions inform judgment and regulate thought. Trends in Cognitive Science 11, no. 9: 393-9.

Cushman, F., L. Young, and M. Hauser. 2006. The role of conscious reasoning and intuition in moral judgment. Psychological Science 17, no. 12: 1082-9.

Damasio, A.R. 2000. Descartes' error: Emotion, reason, and the human brain. New York: Putnam.

Ericsson, K.A., and N. Charness. 1994. Expert performance: Its structure and acquisition. American Psychologist 49, no. 8: 725-47.

Forsyth, D.R., E.H. O’Boyle, Jr., and M.A. McDaniel. 2008. East meets west: A meta-analytic investigation of cultural variations in idealism and relativism. Journal of Business Ethics 83: 813-33. doi: 10.1007/s10551-008-9667-6.

Gick, M.L. 1986. Problem-solving strategies. Educational Psychologist 21, nos. 1-2: 99-120.

Glasman, L., and D. Albarracin. 2006. Forming attitudes that predict future behavior: A meta-analysis of the attitude-behavior relation. Psychological Bulletin 132, no. 5: $778-822$.

Gregory, S., M.J.W. Lee, A. Ellis, B. Gregory, D. Wood, M. Hillier, et al. 2010. Australian higher education institutions transforming the future of teaching and learning through $3 \mathrm{D}$ virtual worlds. In Curriculum, technology \& transformation for an unknown future. Proceedings ascilite Sydney 2010, ed. C. Steel, M.J. Keppell, and P. Gerbic, 399-415. Sydney: Ascilite.

Hatano, G., and K. Inagaki. 1984. Two courses of expertise. Research and Clinical Center for Child Development 6: 27-36.

Hatano, G., and Y. Oura. 2003. Commentary: Reconceptualizing school learning using insight from expertise research. Educational Researcher 32, no. 8: 26-9.

Herrington, J., and R. Oliver. 2000. An instructional design framework for authentic learning environments. Educational Technology, Research and Development 48, no. 3: 23-48.

Herrington, J., T. Reeves, and R. Oliver. 2007. Immersive learning technologies: Realism and online authentic learning. Journal of Computing in Higher Education 19, no. 1: $80-99$.

Jonassen, D. 1997. Instructional design models for well-structured and ill-structured problem-solving learning outcomes. Educational Technology Research and Development 45, no. 1: 65-94.

Jonassen, D. 2000. Toward a design theory of problem solving. Educational technology research and development 48, no. 4: 63-85.

Kitchener, K.S. 1983. Cognition, metacognition, and epistemic cognition. Human Development 26: 222-32.

Lave, J. 1988. Cognition in practice: Mind mathematics and culture in everyday life. Melbourne, Australia: Cambridge University Press.

Mennecke, B.E., J.L. Triplett, L.M. Hassall, Z.J. Conde, and R. Heer. 2011. An examination of a theory of embodied social presence in virtual worlds. Decision Sciences 42, no. 2: 413-50.

Newell, A., and H.A. Simon. 1961. GPS, A program that simulates human thought. In Lernende Automaten, ed. H. Billing, 109-124. Munchen: R. Oldenbourg. 
Peterson, M. 2006. Learner interaction management in an avatar and chat-based virtual world. Computer Assisted Language Learning 19, no. 1: 79-103.

Schraw, G., M.E. Dunkle, and L.D. Bendixen. 1995. Cognitive processes in well-defined and ill-defined problem solving. Applied Cognitive Psychology 9: 523-38.

Schultze, U., S.R. Hiltz, B. Nardi, J. Rennecker, and S. Stucky. 2008. Using synthetic worlds for work and learning. Communications of the Association for Information Systems 22: 351-70.

Schwarz, N. 2000. Emotion, cognition, and decision making. Cognition \& Emotion 14, no. 4: $433-40$.

Shaffer, D.W. 2006. Epistemic frames for epistemic games. Computers \& Education 46, no. 3: 223-34.

Shao, R., K. Aquino, and D. Freeman. 2008. Beyond moral reasoning: A review of moral identity research and its implications for business ethics. Business Ethics Quarterly 18, no. 4: $513-40$.

Shin, N., D.H. Jonassen, and S. McGee. 2003. Predictors of well-structured and ill-structured problem solving in an astronomy simulation. Journal of Research in Science Teaching 40, no. 1: 6-33.

Slater, M., A. Sadagic, M. Usoh, and R. Schroeder. 2000. Small-group behavior in a virtual and real environment: A comparative study. Presence: Teleoperators \& Virtual Environments 9, no. 1: 37-51.

Squire, K. 2006. From content to context: Videogames as designed experience. Educational Researcher 35, no. 8: 19-29.

Taylor, T.L. 2002. Living digitally: Embodiment in virtual worlds. In The social life of avatars: Presence and interaction in shared virtual environments, ed. R. Schroeder, 40-62. London: Springer-Verlag.

Ulicsak, M., and M. Wright. 2010. Games in education: Serious games. Bristol, UK: FutureLab.

Weibel, D., D. Stricker, B. Wissmath, and F.W. Mast. 2010. How socially relevant visual characteristics of avatars influence impression formation. Journal of Media Psychology 22, no. 1: $37-43$. 